\title{
Securing Cranial Horizontal-Vertical Valve in Proper Orientation for Use in Ventriculoperitoneal Shunting: Technical Note
}

\author{
Aaron J. Clark ${ }^{1}$, Martin J. Rutkowski ${ }^{2}$, Michael W. McDermott ${ }^{2}$ \\ 1. University of California, San Francisco 2. Department of Neurological Surgery, University of California, \\ San Francisco
}

$\square$ Corresponding author: Aaron J. Clark, aaronclark83@hotmail.com

Disclosures can be found in Additional Information at the end of the article

\section{Abstract}

Introduction: There are several options for cerebrospinal fluid diversion in patients with normal pressure hydrocephalus. Fixed and programmable valves, with or without anti-siphon devices, have been used for ventriculoperitoneal shunts and horizontal-vertical valves for lumboperitoneal shunts. Recently, a horizontal-vertical valve was developed for ventriculoperitoneal shunts and has been demonstrated to be efficacious. This series describes the surgical method we employ for securing the valve in a true vertical position.

Materials and Methods: The bone of the retroauricular region above the superior nuchal line is exposed. A trough is made in the bone in the vertical orientation to seat the valve which is then secured with a titanium plate and screw.

Results: The technique has been used without complications in nine patients to date. No patient has exhibited signs of shunt malfunction.

Conclusion: The authors propose this method for the safe, secure maintenance of an horizontal-vertical valve used for ventriculoperitoneal shunting in the upright vertical position.

Received 11/29/2013

Review began 11/30/2013

Published 01/24/2014

๑) Copyright 2014

Clark et al. This is an open access article distributed under the terms of the Creative Commons Attribution License CC-BY 3.0., which permits unrestricted use, distribution, and reproduction in any medium, provided the original author and source are credited.
Categories: Neurosurgery

Keywords: normal pressure hydrocephalus, horizontal vertical valve, ventriculoperitoneal shunt

\section{Introduction}

Cerebrospinal fluid (CSF) diversion is standard treatment for symptomatic communicating hydrocephalus and can lead to functional improvement [1-2]. Lumboperitoneal (LP) shunts are used in the treatment of normal pressure hydrocephalus (NPH), and recent innovations have made the procedure safer [3]. Subdural hygroma from overdrainage is a relatively common and potentially serious complication of shunting [4]. Horizontal-vertical (HV) valves have been used in combination with lumboperitoneal (LP) shunt systems to prevent overdrainage for several years. These incorporate a lower pressure, spring-actuated, ball-in-cone device in series with a higher pressure gravitational valve [5]. When the patient is supine, the valve function depends on the lower pressure valve; when the patient stands vertically, CSF flow is directed by the combined resistance of the lower and higher pressure gravitational valve. We have 


\section{Cureus}

demonstrated that the HV valve for LP shunting can be performed safely and may be associated with lower incidence of overdrainage phenomena (postural headache, subdural hygroma, hematoma, acquired Chiari malformation) [6]. We also demonstrated a parallel objective improvement in gait, urinary incontinence, and memory. In general, however, ventriculoperitoneal (VP) shunts are more commonly placed, likely due to surgeon preference or failure of LP shunt. HV valves designed for use with VP shunt systems have recently been developed. They have been demonstrated to be safe and durable [7]. A recent randomized, controlled clinical trial indicated that they are associated with statistically significantly lower rates of overdrainage compared to standard VP shunt systems [8]. Position of the HV valve on the head is important [9]. Maintenance of the position of the valve along the vertical axis of the patient is critical. We have previously demonstrated migration of the HV valve when used for LP shunting [10]. To prevent HV valve migration in VP shunting, we have developed a surgical technique to rigidly fix the HV valve to the patient's skull in the vertical position. Our goal is to demonstrate the efficacy and safety of this technique. 


\section{Cureus}
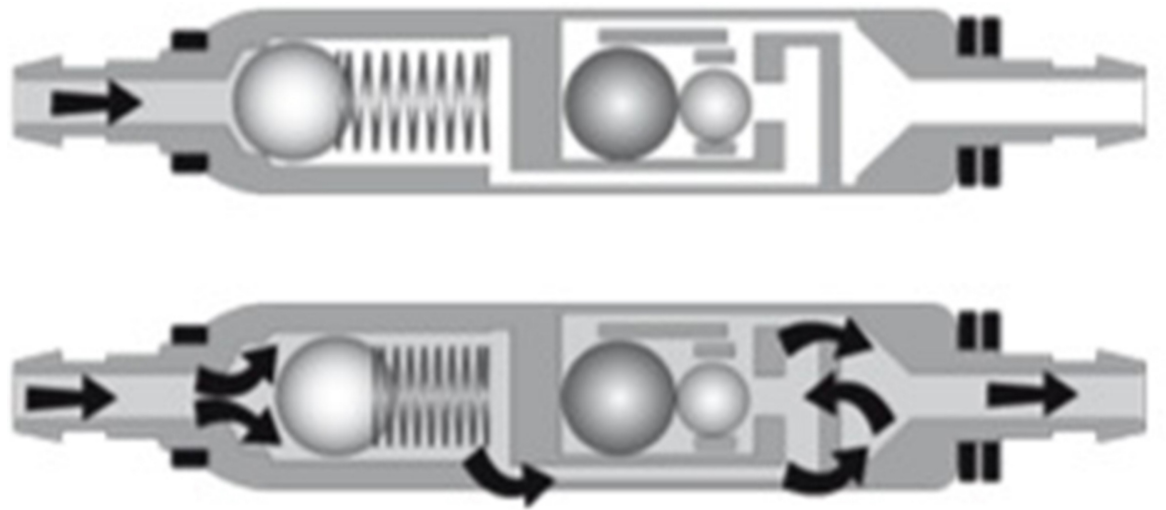

A
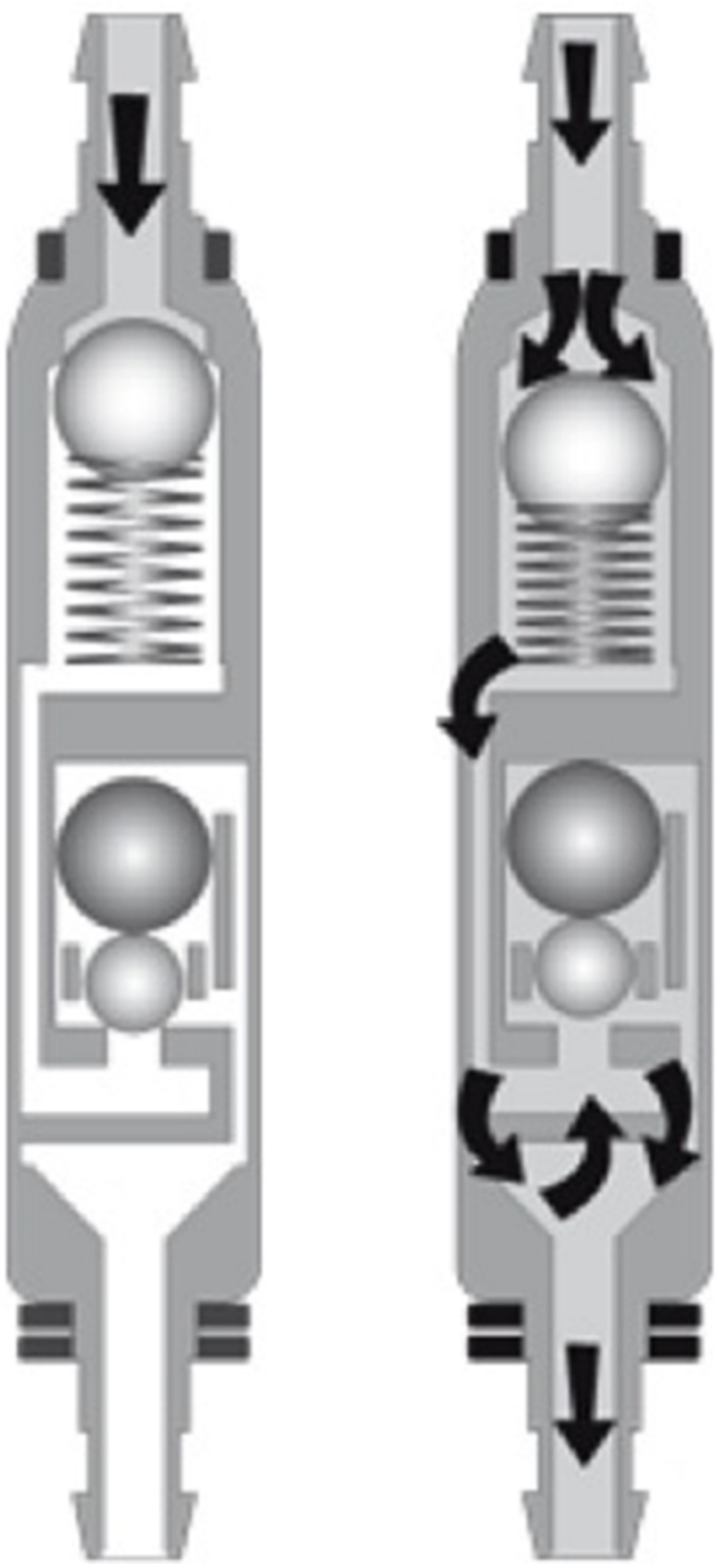

FIGURE 1: Cranial Horizontal-Vertical Valve 


\section{Cureus}

\section{Materials And Methods}

\section{Patient selection}

Adult patients with a diagnosis of NPH were included in the study. All patients consented to the placement of VP shunt with HV valve. All patients underwent the placement of the HV valve using the surgical technique described below. Retrospective chart review was performed to extract preoperative imaging and symptoms as well as operative notes, postoperative imaging, and follow-up. This study was approved by the UCSF Institutional Review Board.

\section{Surgical technique}

The skin behind the ear is clipped of hair and a curvilinear incision is marked out so that twothirds of the incision is above the superior nuchal line (Figure 2). Once the skin is reflected, this allows for exposure of the bone above the insertion of the suboccipital muscles. After the peritoneal tubing and proximal catheter and reservoir have been placed, both ends of the tubing are brought to the retroauricular wound and connected to the HV valve (Aesculap, Inc.). The valve is then aligned to a vertical position for the upright anatomic position and the bone marked for the length and width of the valve (Figure 3). A cutting burr is then used to create a trough in the bone into which the valve will sit (Figure 4). Using two hemostat clamps, a titanium plate (12 $\mathrm{mm}$ in length) is molded to accept the body of the valve to ensure the plate, once secured to the bone, does not compress the valve (Figure 5). The plate is secured at one end to the skull with two $4 \mathrm{~mm}$. screws. The proximal catheter is cut to length and secured to the valve with 2.0 sutures, and traction is gently applied to the distal peritoneal end to remove any excess catheter length. The wound is closed in a standard two-layer fashion, and the resulting wound shows no prominence of the valve body through the skin (Figure 6 ).

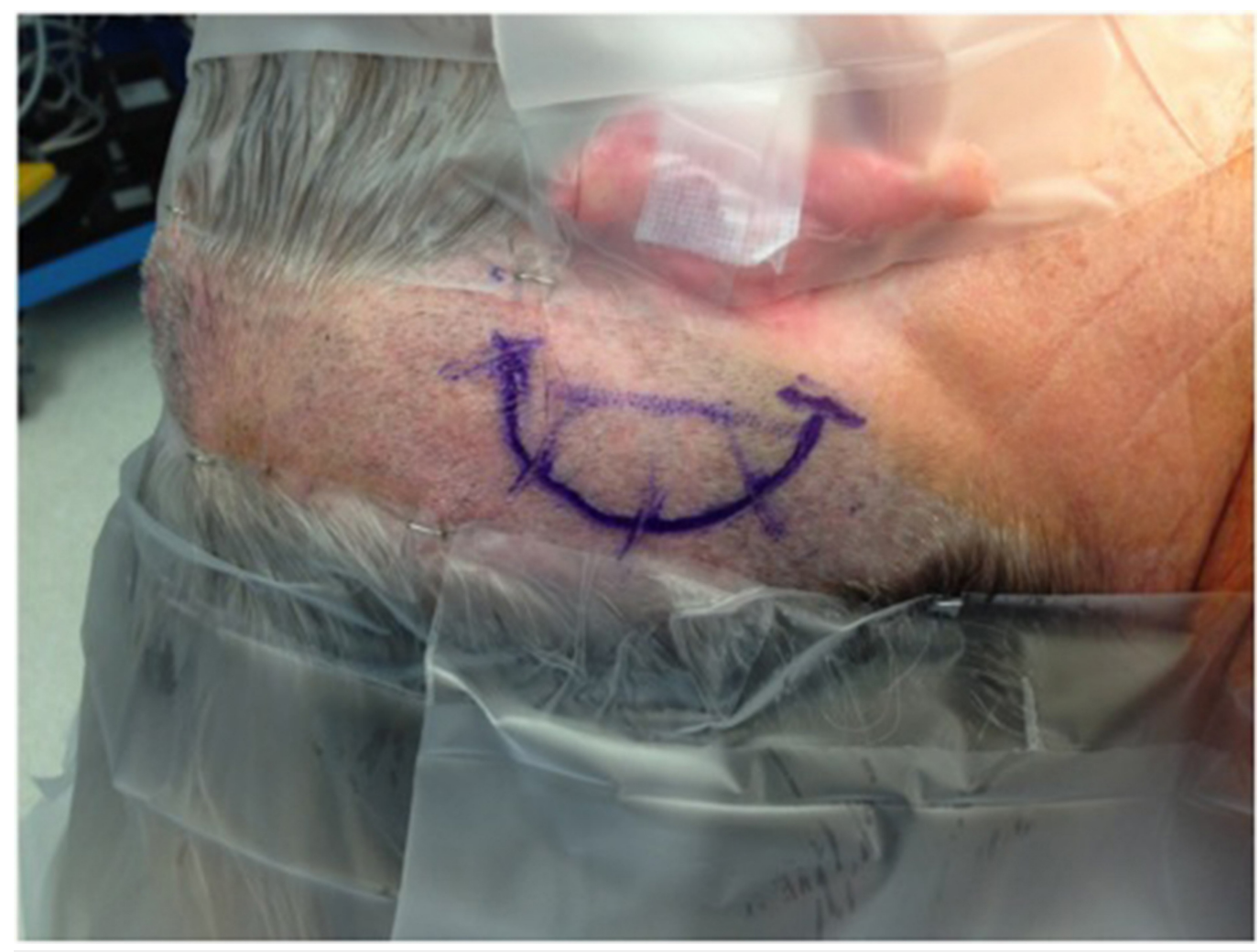

FIGURE 2: The skin behind the ear is clipped of hair and a 


\section{Cureus}

curvilinear incision is marked out so that two-thirds of the incision is above the superior nuchal line.

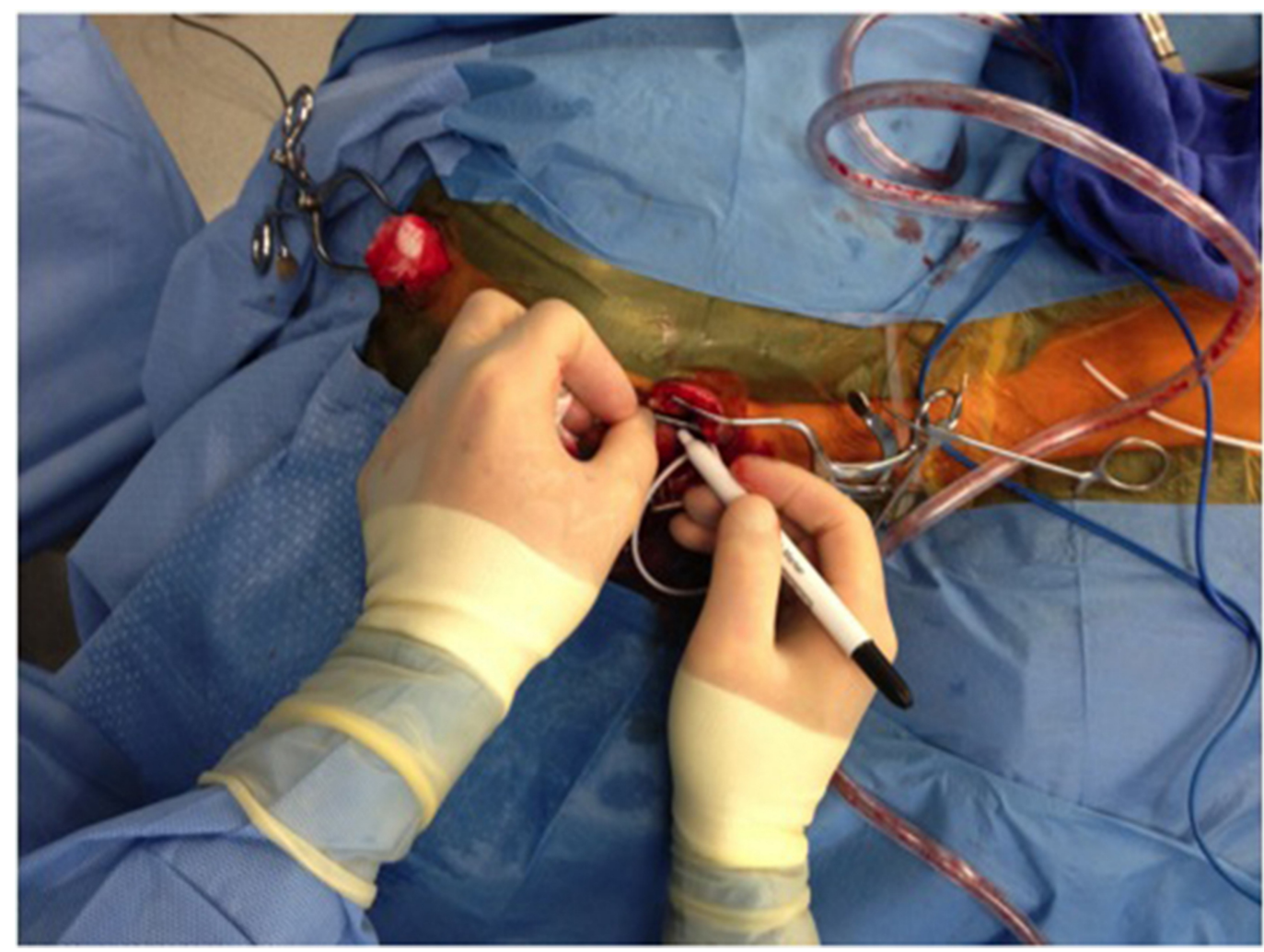

FIGURE 3: The valve is then aligned to a vertical position for the upright anatomic position and the bone marked for the length and width of the valve. 


\section{Cureus}

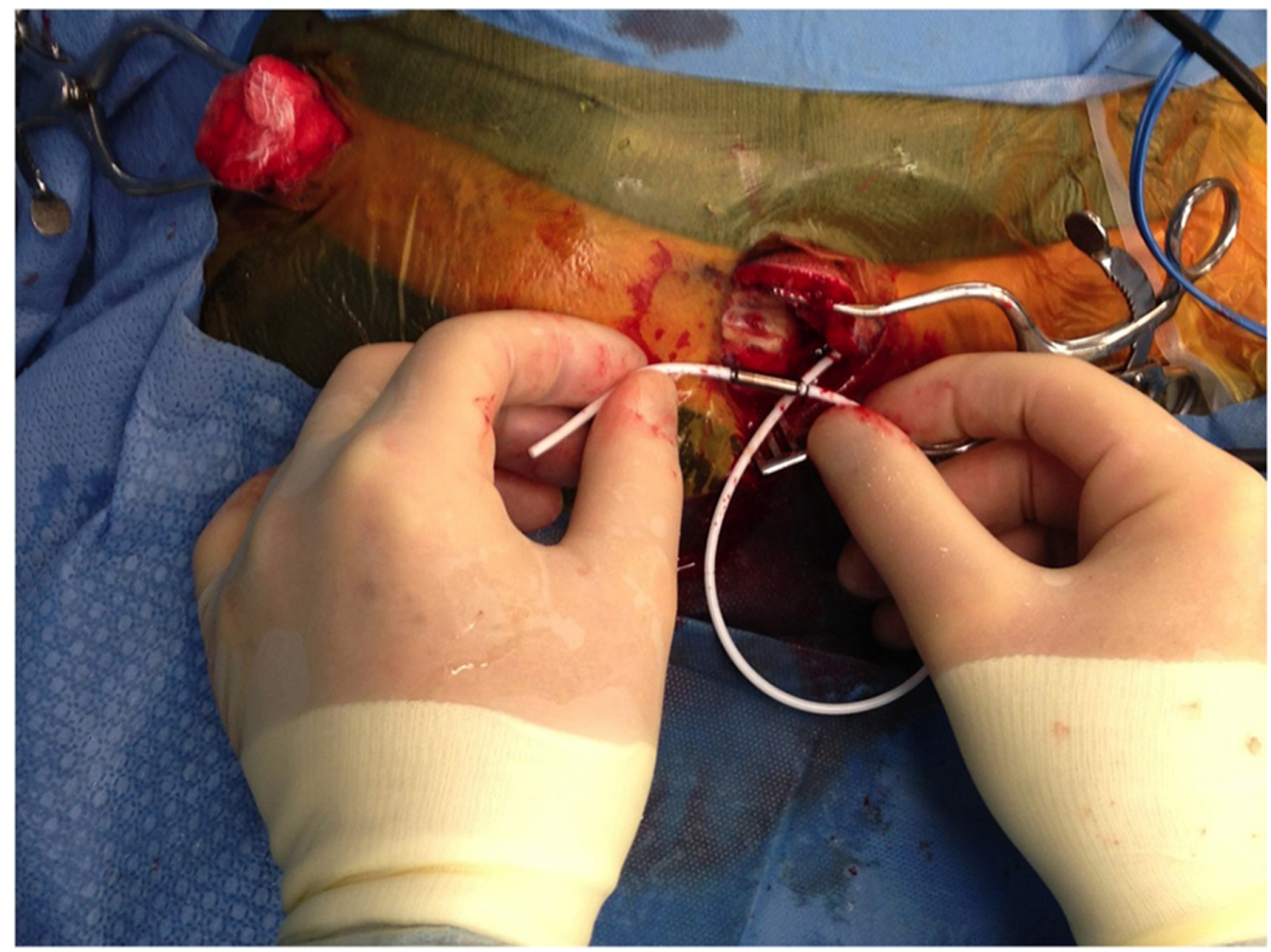

FIGURE 4: A cutting burr is then used to create a trough in the bone into which the valve will sit.

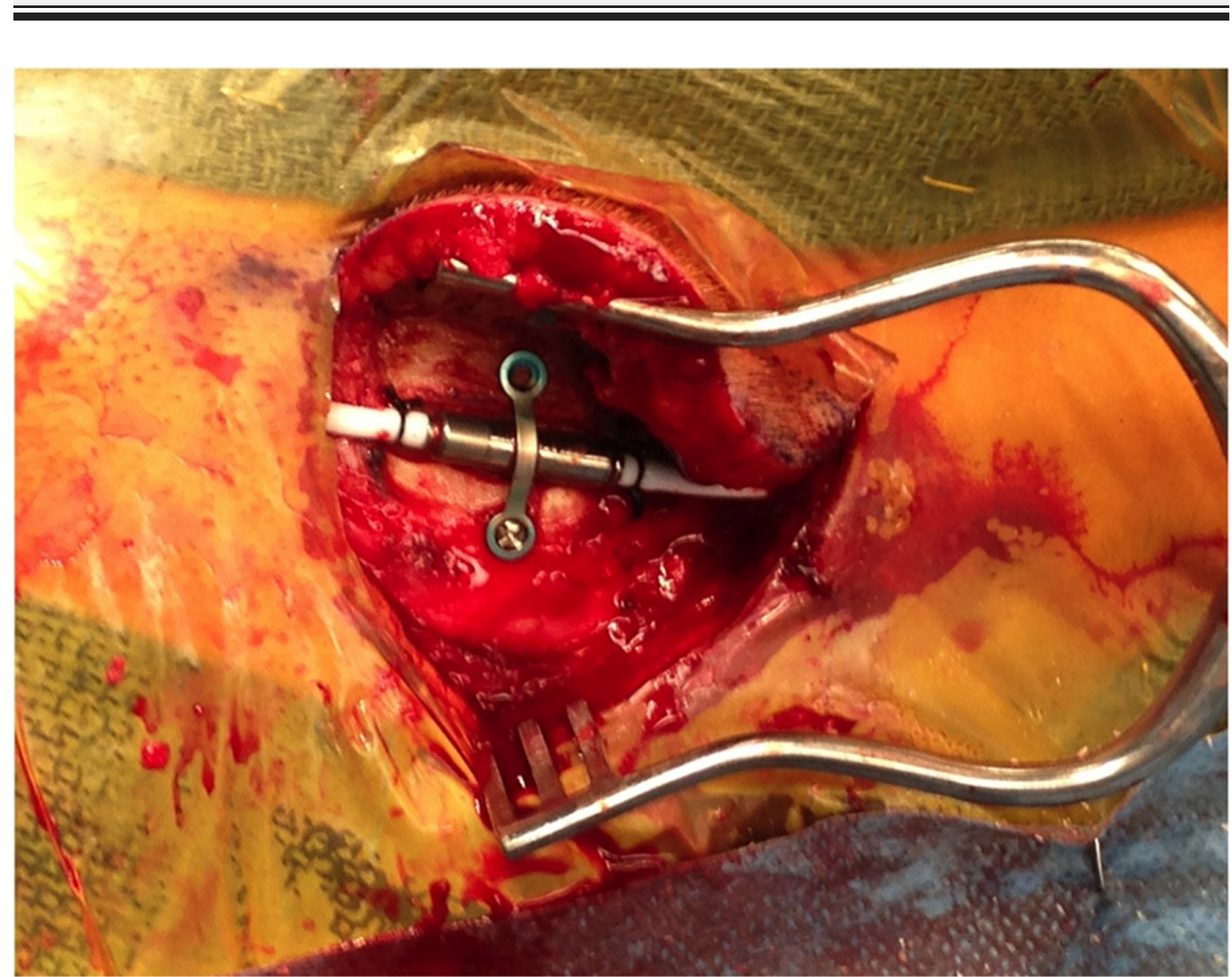

FIGURE 5: Using two hemostat clamps, a titanium plate (12 mm 


\section{Cureus}

in length) is molded to accept the body of the valve to ensure the plate, once secured to the bone, does not compress the valve.

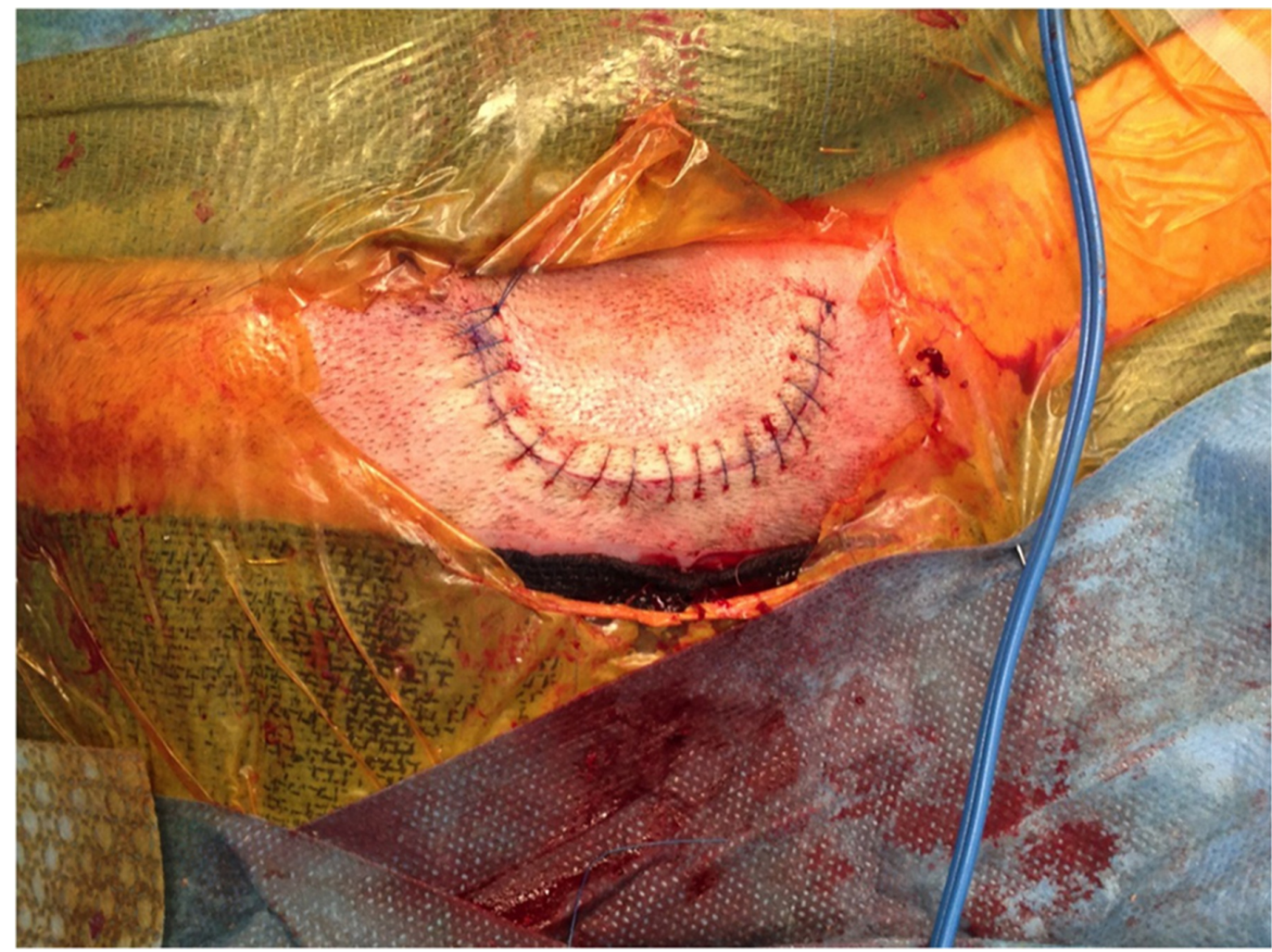

FIGURE 6: The wound is closed in a standard two-layer fashion, and the resulting wound shows no prominence of the valve body through the skin.

\section{Results}

Nine patients with NPH have been treated with the HV valve fixed to the skull as described above (Table 1). One patient was 45 years old, but still demonstrated the signs and symptoms of NPH that improved with a trial of CSF drainage. The method described above has been used with acceptable cosmetic results, no complaints of pain behind the ear, and no evidence of shunt valve dysfunction. No patients experienced symptoms or radiographic signs of overdrainage. No patients required revision of the valve or ventricular catheter. All patients underwent postoperative CT scan and subsequent imaging, if clinically indicated. On the most recent follow-up, CT scans demonstrated smaller ventricles in six patients, stable size in two patients, and larger ventricles in one patient (Table 2). No patients clinically worsened during the follow-up period. Most relevant to this technical note, lateral scout images from follow-up CT scans demonstrated stable vertical position of the HV valve in all patients (Figure 7). 


\section{Cureus}

\section{Characteristic}

Age (years)

Median (range)

Gender

Female

Primary symptoms

Gait disturbance

Memory impairment

Urinary incontinence

Diagnosis

NPH

Follow-up (months)

Mean (range) n

$\%$

$71(45-83)$

$\mathrm{n} / \mathrm{a}$

6

67

9

100

6

9

100

$5(1-16)$

$\mathrm{n} / \mathrm{a}$

TABLE 1: Demographics of the patient series. 


\section{Cureus}

\begin{tabular}{|c|c|c|c|c|}
\hline Patient & Presenting Symptom & $\begin{array}{l}\text { Most Recent } \\
\text { Ventricular Size }\end{array}$ & Symptom Outcome & $\begin{array}{l}\text { Length of Follow-up } \\
\text { (Months) }\end{array}$ \\
\hline 1 & Gait disturbance and Incontınence & Smaller & Improved gait & 1 \\
\hline 2 & $\begin{array}{l}\text { Galt disturbance, Incontınence, } \\
\text { memory impairment }\end{array}$ & Stable & $\begin{array}{l}\text { Improved galt and } \\
\text { continence }\end{array}$ & 16 \\
\hline 3 & Gait disturbance & Smaller & Improved gait & 6 \\
\hline 4 & $\begin{array}{l}\text { Gait disturbance and memory } \\
\text { impairment }\end{array}$ & smaller & Improved gait & 8 \\
\hline 5 & Gait disturbance & Smaller & Improved gait & 5 \\
\hline 6 & $\begin{array}{l}\text { Gait disturbance, incontinence, } \\
\text { memory impairment }\end{array}$ & Smaller & Stable & 7 \\
\hline 7 & $\begin{array}{l}\text { Gait disturbance, incontinence, } \\
\text { memory impairment }\end{array}$ & Smaller & Improved gait & 3 \\
\hline 8 & Gait disturbance and incontinence & Larger & Stable & 1 \\
\hline 9 & $\begin{array}{l}\text { Galt disturbance, incontinence, } \\
\text { memory impairment }\end{array}$ & Stable & Improved gait & 2 \\
\hline
\end{tabular}

TABLE 2: Outcomes and follow-up of the patients treated with the novel technique. 


\section{Cureus}
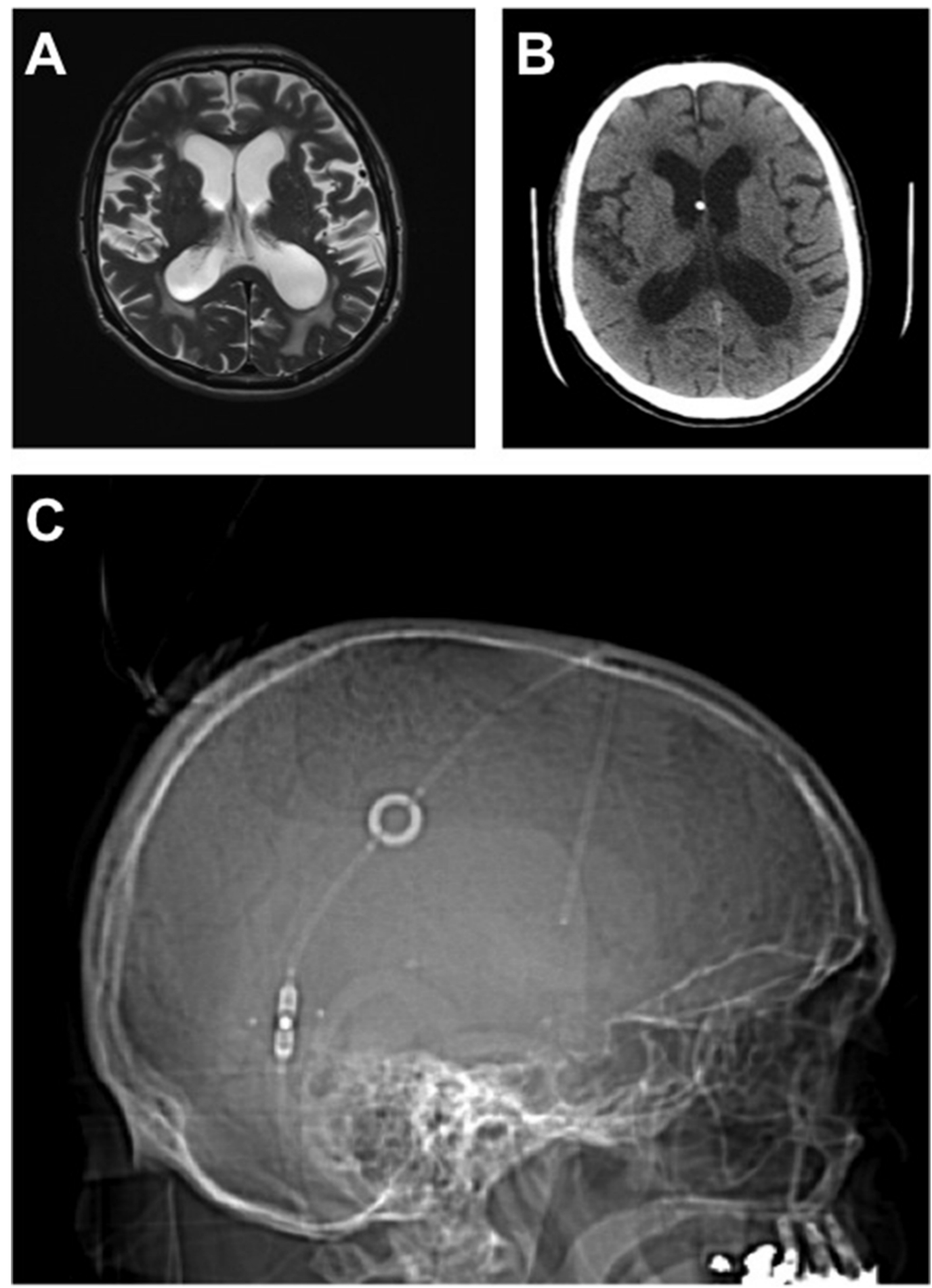

FIGURE 7: lateral scout images from follow-up CT Scans demonstrated stable vertical position of the $\mathrm{HV}$ valve in all patients.

\section{Discussion}

The treatment of NPH using either VP or LP shunt systems is not without problems [4, 11]. We have previously described our results using a HV valve system in an LP shunt application [10]. There were 46 patients treated with a HV valve LP shunt, and in nine patients, there were 
complications related to disconnection, migration, or obstruction of the valve system. Based on the reports of a recent European trial using a HV valve for a VP shunt system, we decided to explore the use of this valve and realized that, similar to the LP shunt valve system, there was no defined method for securing the valve orientation to ensure proper consistent function [7-8]. The method described above appears to secure the valve in optimal position without mechanical or cosmetic problems.

The LP shunt HV valve is designed with a pre-valve reservoir connected to a valve which utilizes the effect of gravity on small metal spheres within two cylinders arranged in parallel. The valve contains two ball-in-cone valve mechanisms [12]. The inlet side of the valve, or proximal valve, is comprised of a spring-actuated (lower) pressure mechanism and the outlet, or distal, side of the valve has a gravity-actuated (higher) pressure mechanism. When the patient stands, gravity acts on the ball-in-cone inlet spring valve, pulling it down in the chamber away from inlet cone, and reducing resistance to flow. At the same time in the distal chamber, the balls are pulled into the cone valve increasing resistance to flow, and it is the distal valve that controls CSF flow in the vertical position. In the horizontal position, the effect of gravity is eliminated so the position of the balls is reversed and the inlet spring-ball valve controls CSF flow. There are two pressure ranges of horizontal valves $(85-125 \mathrm{~cm}, 50-80 \mathrm{~cm}$.) and three vertical pressures for each of the two horizontal ranges.

The GAV valve utilizes the same principle of gravity acting on a tantalum weight ball within a chamber distal to the inlet valve which is a ball-spring valve [13]. In the horizontal position, CSF flow is governed only by the resistance of the ball-spring valve, whereas in the upright position, the resistance of the gravitational ball is added to the resistance. While the inlet pressure has two pressure settings $(5,10 \mathrm{~cm}$.), the outlet valve pressure can be varied based on patient height (30, 35, 40, $50 \mathrm{~cm}$.).

With both valve systems, the pressure created by the effect of gravity on the ball-in-cone units can vary depending on the orientation of the valve in the patient. Securing the HV valve in the flank so that it remains perfectly horizontal is problematic [10]. Whether this significantly influences the clinical functioning of the valve is unknown. However, pre-implantation testing of the LP HV valve clearly demonstrates that resistance to flow of water in a manometer is related to the position of the valve unit with respect to a vertical plane. The less vertical the valve is held, the slower the flow of fluid out of the manometer until it reaches the lower limit of opening pressure for the vertical unit. In patients with VP shunts, Kaestner, et al. demonstrated significant under-drainage in patients who were bedridden with an HV valve, underscoring the potential importance of valve orientation [14]. Park, et al. analyzed valve inclination with VP shunt patients in the standing position, and its relationship to postoperative change in ventricular size, and found that anterior valve inclination can lead to underdrainage [15]. Since the GAV valve is for VP shunting, placement of the valve over bone offers the opportunity to secure the orientation of the valve in a rigid fashion that makes it more likely the valve will function as designed. Drilling a trough in the bone to accommodate the body of the valve ( $4.6 \mathrm{~mm}$. diameter) is simple enough; however, molding the securing plate is important as excessive pressure on the body of the valve may cause valve dysfunction. The trough is drilled with an acute angle instead of a tapered angle; therefore, the sides' cylindrical valve abut the acute edges of the trough to prevent vertical migration. However, because the $\mathrm{HV}$ valve is cylindrical, it cannot be secured to the subgaleal space.

\section{Conclusions}

To date, and with relatively short follow-up, this method has been used in nine patients without problems. Surgeons can consider this method for the safe, secure implantation of the GAV valve in a vertical orientation for the treatment of hydrocephalus. 


\section{Additional Information \\ Disclosures}

Human subjects: Consent was obtained by all participants in this study. The UCSF Institutional Review Board issued approval N/A. Animal subjects: All authors have confirmed that this study did not involve animal subjects or tissue. Conflicts of interest: In compliance with the ICMJE uniform disclosure form, all authors declare the following: Payment/services info: All authors have declared that no financial support was received from any organization for the submitted work. Financial relationships: All authors have declared that they have no financial relationships at present or within the previous three years with any organizations that might have an interest in the submitted work. Other relationships: All authors have declared that there are no other relationships or activities that could appear to have influenced the submitted work.

\section{References}

1. Bergsneider M, Black PM, Klinge P, Marmarou A, Relkin N: Surgical management of idiopathic normal-pressure hydrocephalus. Neurosurg. 2005, 57:S29-39.

2. Cage TA, Auguste KI, Wrensch M, Wu YW, Gupta N: Self-reported functional outcome after surgical intervention in patients with idiopathic normal pressure hydrocephalus. J Clin Neurosci. 2011, 18:649-54. 10.1016/j.jocn.2010.08.028

3. Maa J, Carter JT, Kirkwood KS, Gosnell JE, Wang V, McDermott MW: Technique for placement of lumboperitoneal catheters using a combined laparoscopic procedure with the Seldinger micropuncture technique. J Am Coll Surg. 2008, 207:e5-7. 10.1016/j.jamcollsurg.2008.03.015

4. Boon AJ, Tans JT, Delwel EJ, Egeler-Peerdeman SM, Hanlo PW, Wurzer HA, Avezaat CJ, de Jong DA, Gooskens RH, Hermans J: Dutch normal-pressure hydrocephalus study: Randomized comparison of low- and medium-pressure shunts. J Neurosurg. 1998, 88:490-5.

5. Kiefer M, Eymann R, Meier U: Five years experience with gravitational shunts in chronic hydrocephalus of adults. Acta Neurochir (Wien). 2002, 144:755-767.

6. Bloch O, McDermott MW: Lumboperitoneal shunts for the treatment of normal pressure hydrocephalus. J Clin Neurosci. 2012, 19:1107-1111. 10.1016/j.jocn.2011.11.019

7. Sprung C, Schlosser HG, Lemcke J, et al.: The adjustable proGAV shunt: A prospective safety and reliability multicenter study. Neurosurg. 2010, 66:465-74.

10.1227/01.NEU.0000365272.77634.6B

8. Lemcke J, Meier U, Müller C, et al: Safety and efficacy of gravitational shunt valves in patients with idiopathic normal pressure hydrocephalus: A pragmatic, randomised, open label, multicentre trial (SVASONA). J Neurol Neurosurg Psychiatry. 2013, 84:850-7. 10.1136/jnnp2012-303936

9. Stockhammer F, Miethke C, Knitter T, Rohde V, Sprung C: Flow-related noise in patients with ventriculoperitoneal shunt using gravitational adjustable valves. Acta Neurochir (Wien). 2013, Epub ahead of print.

10. Wang VY, Barbaro NM, Lawton MT, Pitts L, Kunwar S, Parsa AT, Gupta N, McDermott MW: Complications of lumboperitoneal shunts. Neurosurg. 2007, 60:1045-9.

11. Hebb AO, Cusimano MD: Idiopathic normal pressure hydrocephalus: a systematic review of diagnosis and outcome. Neurosurg. 2001, 49:1166-1186.

12. Miethke C, Affeld K: A new valve for the treatment of hydrocephalus . Biomed Tech (Berl). 1994, 39:181-7.

13. Meier U, Kiefer M, Sprung C: Evaluation of the Miethke dual-switch valve in patients with normal pressure hydrocephalus. Surg Neurol. 2004, 61:119-28.

14. Kaestner S, Kruschat T, Nitzsche N, Deinsberger W: Gravitational shunt units may cause under-drainage in bedridden patients. Acta Neurochir (Wien). 2009, 151:217-21. 10.1007/s00701-009-0215-7

15. Park J, Kim GJ, Hwang SK: Valve inclination influences the performance of gravity-assisted valve. Surg Neurol. 2007, 68:14-18. 